\title{
Коррекция характеристик обратного восстановления высоковольтных инжекционных 4H-SiC диодов с помощью протонного облучения
}

\author{
(С) П.А. Иванов, М.Ф. Кудояров, А.С. Потапов, Т.П. Самсонова
}

Физико-технический институт им. А.Ф. Иоффре Российской академии наук, 194021 Санкт-Петербург, Россия

E-mail: Pavel.Ivanov@mail.ioffe.ru

Поступила в Редакцию 28 января 2019 г.

В окончательной редакции 31 января 2019 r.

Принята к публикации 31 января 2019 г.

Исследовано влияние протонного облучения на электрические характеристики высоковольтных (3 кВ) инжекционных диодов на основе $4 H$-SiC. Облучение проводилось через никелевую маску толщиной 10 мкм, энергия протонов и доза облучения составляли $2.8 \mathrm{MэB} \mathrm{и} 4 \cdot 10^{11} \mathrm{~cm}^{-2}$ соответственно. После облучения дифференциальное сопротивление диодов в прямом направлении увеличивалось на $\sim 35 \%$, заряд обратного восстановления диодов уменьшался в $\sim 3$ раза, а характер переключения с прямого направления на обратное становился „жестким“.

DOI: 10.21883/FTP.2019.06.47743.9073

\section{1. Введение}

Облучение легкими высокоэнергетическими частицами - электронами, протонами, $\alpha$-частицами - широко применяется для коррекции динамических характеристик кремниевых силовых диодов (см., например, $[1,2])$. При облучении создаются дополнительные рекомбинационные центры (в том числе локально), что позволяет корректировать характеристики обратного восстановления диодов. При выборе схемы облучения силовых диодов обычно стремятся добиться минимальных значений времени и заряда обратного восстановления, сохранив при этом малое прямое падение напряжения и так называемый „мягкий“ характер переключения (степень „мягкости“ переключения характеризуют коэффициентом $K$, который определяется как отношение длительности спада обратного тока к длительности фазы его нарастания; для силовых диодов предпочтителен „мягкий“ режим, при котором $K>1$ ). В случае кремниевых силовых диодов такое сочетание параметров достигается путем формирования профильного распределения концентрации рекомбинационных центров в блокирующей базе с максимумом вблизи инжектирующего $p-n_{0}$-перехода. Для создания подобного профиля часто используют облучение протонами [3]. Ранее в работе [4] нами было экспериментально исследовано влияние низкодозного протонного облучения (доза облучения $\left.10^{10}-1.8 \cdot 10^{11} \mathrm{~cm}^{-2}\right)$ на вольт-фарадные характеристики, прямые вольт-амперные характеристики и характеристики обратного восстановления высоковольтных (3 кВ) инжекционных $4 H$-SiC диодов с $p-n_{0}$-переходом (концентрация доноров в $n_{0}$-базе и толщина базы составляли $5 \cdot 10^{15} \mathrm{~cm}^{-3}$ и 20 мкм соответственно). Облучение проводилось протонами с энергией $1.8 \mathrm{MэВ} \mathrm{через}$ никелевую маску толщиной 10 мкм. Энергия протонов и толщина Ni-маски выбирались так, чтобы пробег протонов в карбиде кремния приблизительно равнялся глубине залегания $p-n_{0}$-перехода. Было показано, что протонное облучение не вызывает сколько-нибудь заметного уменьшения концентрации основных носителей в диодах, уменьшает время жизни неравновесных носителей при низком уровне инжекции (в десятки раз при максимальной дозе облучения), уменьшает заряд обратного восстановления диодов при высоком уровне инжекции (до 3 раз при максимальной дозе облучения). После облучения диоды сохраняли „мягкий“ характер восстановления, что свидетельствовало о том, что облучение приводило главным образом к снижению коэффициента инжекции $p-n_{0}$-перехода. Однако режим ,жесткого“ восстановления тоже представляет интерес [5], поскольку в этом режиме работают, например, высоковольтные импульсные диоды - дрейфовые диоды с резким восстановлением (ДДРВ, в этом случае $K \ll 1)$. В настоящей работе нами были продолжены экспериментальные исследования влияния протонного облучения на характеристики 3 кВ 4H-SiC диодов: проводилось облучение протонами с такой энергией, при которой их пробег в карбиде кремния превышает суммарную толщину всех слоев в эпитаксиальной структуре диодов.

\section{2. Образцы}

Для изготовления диодов использовалась коммерческая $4 \mathrm{H}$-SiC пластина с многослойной эпитаксиальной структурой: $p^{++}-p^{+}-p-n_{0}-n^{+}-n_{s}$ (подложка). Концентрации примесей в эмиттерных $p^{++}, p^{+}, p$ - и $n^{+}$-слоях составляют $2 \cdot 10^{19}, 5 \cdot 10^{18}, 4 \cdot 10^{16}$ и $1 \cdot 10^{18} \mathrm{~cm}^{-3}$ соответственно. Толщины эмиттерных $p^{++}, p^{+}, p-$ и $n^{+}$-слоев составляют $0.5,0.5,3$ и 5 мкм соответственно. Концентрация доноров в блокирующей $n_{0}$-базе составляет $5 \cdot 10^{15} \mathrm{~cm}^{-3}$, а ее толщина - 20 мкм (расчетное напряжение лавинного пробоя таких диодов составляет около 3 кВ). Технология изготовления диодных чипов описана в работе [4]. Активная площадь изготовленных диодов составляет 0.36 мм²$^{2}$. Контрольные диоды облу- 


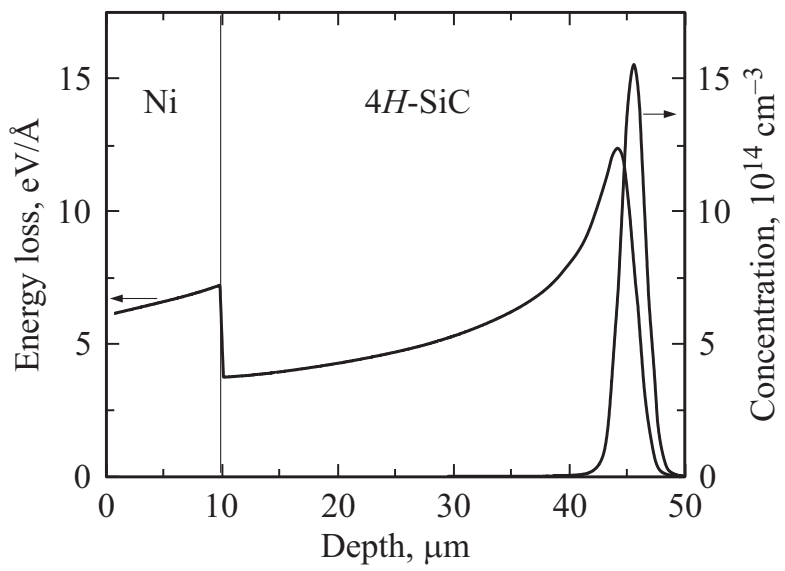

Рис. 1. Концентрационные профили распределения $2.8 \mathrm{MэВ}$ протонов, внедренных в $4 H-\mathrm{SiC}$ диоды, и профиль потерь их энергии (расчет по программе SRIM).

чению не подвергались. Протонное облучение проводилось на уникальной научной установке (УНУ) „Циклотрон ФТИ“. Доза облучения составляла $4 \cdot 10^{11} \mathrm{~cm}^{-2}$. Для расчетов концентрационного профиля распределения внедренных протонов в структуре $\mathrm{Ni} / 4 H-\mathrm{SiC}$ и профиля потерь их энергии на длине пробега использовался программный пакет SRIM [6]. Энергия протонов $(2.8 \mathrm{MэB})$ и толщина маскирующего слоя $\mathrm{Ni}(10$ мкм) выбирались так, чтобы пробег протонов в карбиде кремния превышал суммарную толщину всех эпитаксиальных слоев (рис. 1). После облучения диоды температурному отжигу не подвергались.

\section{3. Измерения и обсуждение результатов}

На рис. 2 показаны типичные характеристики обратного восстановления $(\mathrm{OB})$ необлученных (рис. 2,a) и облученных (рис. $2, b$ ) диодов при их переключении с прямого (квазипостоянного) тока $3 \mathrm{~A}$ на обратное напряжение 400 В. (Скорость переключения тока с прямого на обратный составляла $500 \mathrm{~A} /$ мкс). Как видно, после облучения уменьшались как амплитуда обратного тока, так и время обратного восстановления. В результате заряд ОВ уменьшался в $\sim 3$ раза. Кроме того, существенным образом изменялся характер обратного восстановления: если необлученные диоды показывали довольно „мягкое“ восстановление $(K \approx 6)$, то после облучения коэффициент $K$ уменьшался на порядок величины $(K \approx 0.5)$.

На рис. 3 показаны прямые вольт-амперные характеристики (BAX) необлученных (кривые 1 ) и облученных (кривые 2) диодов, измеренные при токах до 1 А (измерения проводились с помощью цифрового характериографа Л2-100 в режиме однократного запуска развертки по напряжению). Как видно, после облучения дифференциальное сопротивление диодов в прямом направлении (при токе 1 А) увеличивалось на $\sim 35 \%$. Ранее в целом ряде работ было показано, что под действием облучения протонами в $n-4 H-\mathrm{SiC}$ происходит образование глубоких акцепторных центров (см., например, [7]). Образованные протонным облучением акцепторные центры могут в принципе играть роль как компенсирующих центров в базе, так и рекомбинационных центров, снижающих время жизни неравновесных носителей. Таким образом, наблюдаемое увеличение сопротивления диодов после облучения может быть вызвано как увеличением омического сопротивления базовой области (за счет уменьшения концентрации основных носителей), так и уменьшением степени модуляции сопротивления базовой области неосновными носителями (за счет уменьшения концентрации инжектированных неосновных носителей). Для проверки влияния облучения на концентрацию основных носителей в базе были проведены измерения вольт-фарадных характеристик (ВФХ) необлученных и облученных диодов (рис. 4). Измерения ВФХ прово-
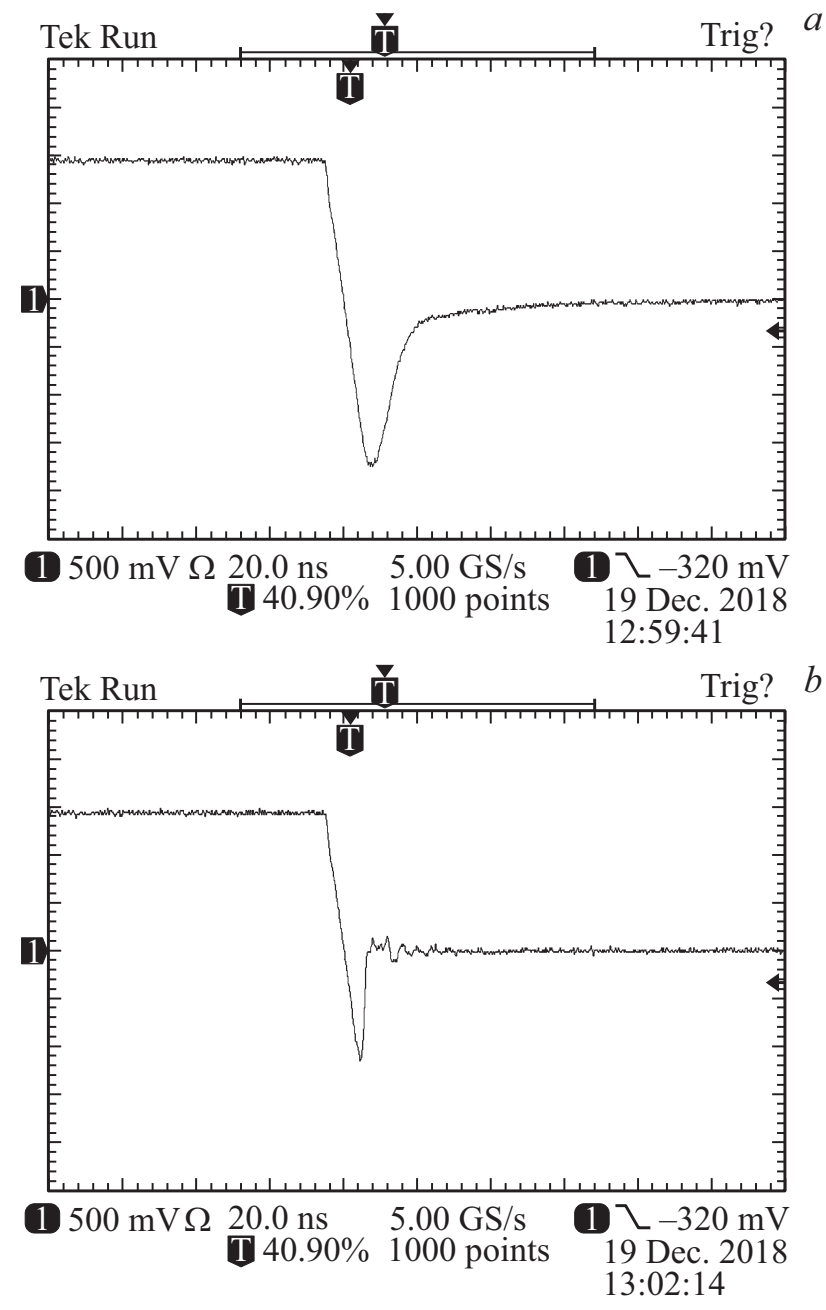

Рис. 2. Типичные характеристики обратного восстановления необлученных $(a)$ и облученных $(b)$ диодов при их переключении с прямого (квазипостоянного) тока $3 \mathrm{~A}$ на обратное напряжение $400 \mathrm{~B}$; масштаб по вертикали $1 \mathrm{~A} /$ дел, масштаб по горизонтали 20 нс/дел. 


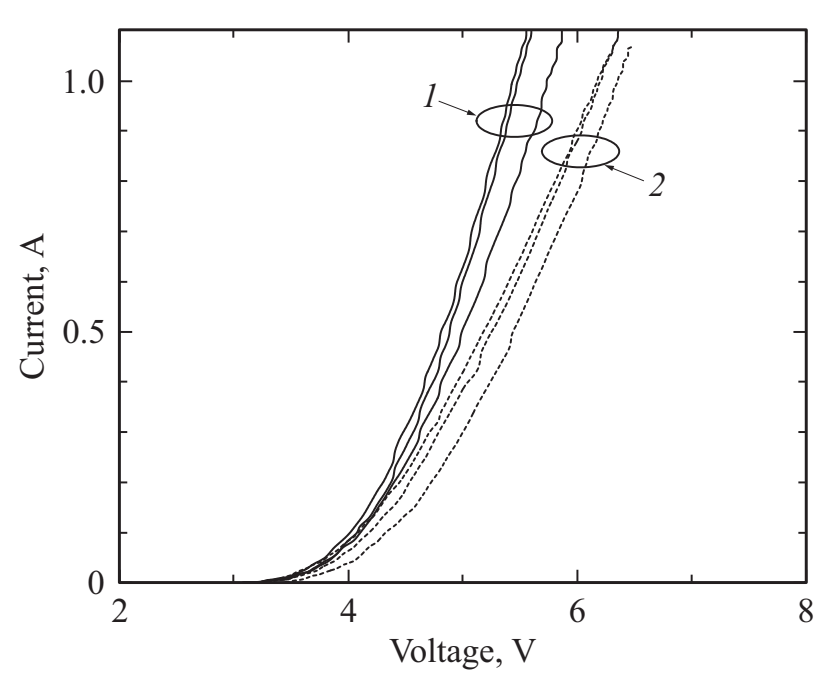

Рис. 3. Прямые вольт-амперные характеристики трех необлученных (кривые 1) и трех облученных (кривые 2) диодов.

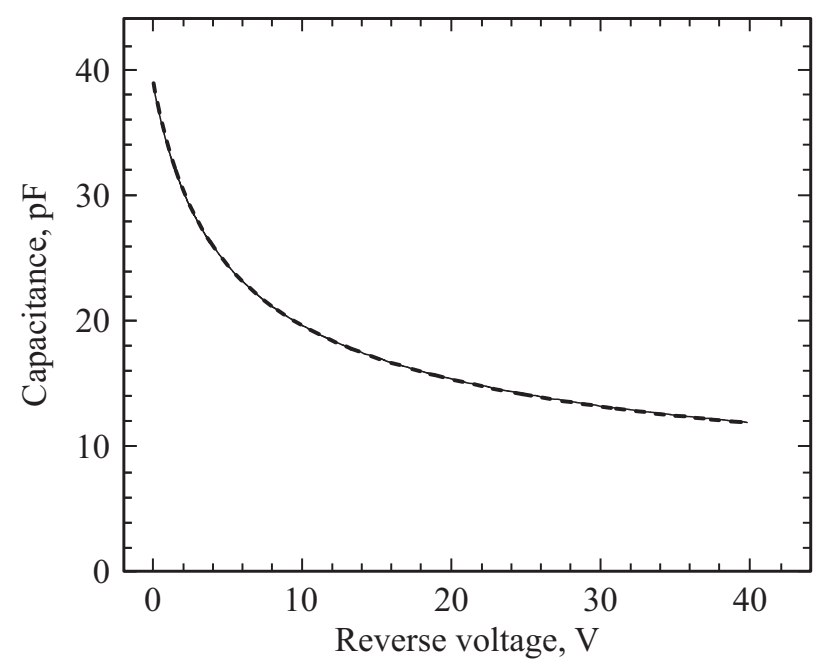

Рис. 4. Вольт-фарадные характеристики необлученных (сплошная линия) и облученных (пунктирная линия) диодов.

дились с помощью цифрового измерителя иммитанса E7-20 на частоте 1 МГц. Как видно, измеренные ВФХ практически идентичны, что свидетельствует о том, что протонное облучение не оказывает сколько-нибудь заметного компенсирующего влияния на концентрацию основных носителей в базовой области диодов. Поэтому логично заключить, что протонное облучение приводит к равномерному уменьшению времени жизни неравновесных носителей в базе и уменьшению степени модуляции сопротивления базы при накачке квазипостоянным током.

\section{4. Заключение}

Таким образом, проведенное в настоящей работе экспериментальное исследование показало возможность эффективной коррекции характера обратного восстановления инжекционных $4 H-\mathrm{SiC}$ диодов с помощью протонного облучения. Трансформация „мягкого“ режима OB в ,жесткий“ может быть использована при конструировании ДДРВ на основе $4 H-\mathrm{SiC}$. В созданных нами ранее $4 H$-SiC ДДРВ со структурой $p^{+}-p-n_{0}-n^{+}[8,9]$ „жесткое“ обратное восстановление реализуется после очень короткой ( 10 нс) импульсной накачки прямым током, за время которой неравновесные носители проникают в базу на незначительную глубину по сравнению с толщиной базы. Иными словами, необходимое для правильной работы ДДРВ сугубо неоднородное распределение инжектированных носителей в $n_{0}$-базе достигается за счет короткой накачки. Однако с помощью протонного облучения тоже оказывается возможным создать подобное распределение, но уже при накачке квазипостоянным током.

\section{Список литературы}

[1] P. Hazdra, J. Vobecký, H. Dorschner, K. Brand. Microelectron. J., 35, 249 (2004).

[2] И.В. Грехов, А.В. Рожков, Л.С. Костина, А.В. Коновалов, Ю.Л. Фоменко. ЖТФ, 10, 50 (2011).

[3] В.В. Козловский. Модифицирование полупроводников пучками протонов (СПб., Наука, 2003).

[4] П.А. Иванов, А.С. Потапов, М.Ф. Кудояров, Т.П. Самсонова. ФТП, 52, 1187 (2018).

[5] В.А. Козлов, В.В. Козловский. ФТП, 35, 769 (2001).

[6] www.srim.org

[7] A.A. Lebedev, A.I. Veinger, D.V. Davydov, V.V. Kozlovski, N.S. Savkina, A.M. Strel'chuk. J. Appl. Phys., 88, 6265 (2000).

[8] П.А. Иванов, О.И. Коньков, Т.П. Самсонова, А.С. Потапов, И.В. Грехов. ФТП, 49, 1558 (2015).

[9] П.А. Иванов, О.И. Коньков, Т.П. Самсонова, А.С. Потапов. Письма ЖТФ, 44, 3 (2018).

Редактор Г.А. Оганесян

\section{Correction of reverse recovery characteristics of high-voltage $4 \mathrm{H}$-SiC junction diodes using proton irradiation}

\author{
P.A. Ivanov, M.F. Kudoyarov, A.S. Potapov, \\ T.P. Samsonova \\ loffe Institute, \\ 194021 St. Petersburg, Russia
}

Abstract The effect of proton irradiation on electrical characteristics of high-voltage $(3 \mathrm{kV}) 4 H-\mathrm{SiC}$ junction diodes have been investigated. The diodes were irradiated through $10-\mu \mathrm{m}$ thick Ni-film. The energy of protons and irradiation dose were $2.8 \mathrm{MeV}$ and $4 \cdot 10^{11} \mathrm{~cm}^{-2}$, respectively. After proton irradiation, the diodes exhibited $35 \%$ increasing in on-state resistance, about 3 times decreasing in the reverse recovery charge with the reverse recovery character being ,hard“. 